\title{
Degradation pathway of triazole fungicides and synchronous removal of transformation products via photo-electrocatalytic oxidation tandem $\mathrm{MoS}_{2}$ adsorption
}

\author{
Junwen Wang ${ }^{1} \cdot$ Xiaoxin Chen $^{1,2}(\mathbb{D})$ Xiaoli Sun ${ }^{1} \cdot$ Miao Liu ${ }^{1} \cdot$ Xingqiang $\mathrm{Wu}^{1} \cdot$ Yichao Gong $^{1} \cdot$ Jianfang Du $^{3}$
}

Received: 29 July 2020 / Accepted: 21 December 2020 / Published online: 2 January 2021

(C) The Author(s) 2021

\begin{abstract}
A simple and effective tandem process of photo-electrocatalytic oxidation (PECO)-MoS $\mathrm{M}_{2}$ adsorption was developed for the synchronous removal of triazole fungicides (TFs) and toxicological transformation products (TPs). In order to accurately identify trace TPs and evaluate degradation pathway during water treatment, a sensitive analytical method was developed on the basis of the stir bar sorptive extraction (SBSE) pretreatment tandem LC-MS/MS technique. Firstly, the typical TFs (PRO, TET, and DIN, $C_{0}=1.0 \mathrm{mg} / \mathrm{L}$ ) in actual water samples were treated under the optimal process (bias voltage $1.8 \mathrm{~V}, \mathrm{pH} 4$, irradiation intensity 50 $\mathrm{mW} / \mathrm{cm}^{2}, 0.05 \mathrm{~g} \mathrm{MoS}_{2} / 100 \mathrm{~mL}, 350 \mathrm{rpm}$, adsorption of $5 \mathrm{~min}$ ). The result indicated that the residues of PRO, TET, and DIN in secondary effluent were $0.0973,0.0617$, and $0.0012 \mathrm{mg} / \mathrm{L}$, respectively, with the removal rates of $90.3 \%, 93.8 \%$, and $99.9 \%$, respectively, undergoing 30-min photo-electrocatalysis and 5-min adsorption. The alkaline medium was favorable for the adsorption of $\mathrm{MoS}_{2}$ to TFs. The assessment results of potential cancer risk indicated that the residues of TFs in secondary effluent were safe for drinking water consumption. Besides, the major TPs were identified via the SBSE-HRLC-MS/MS technique, and one possible transformation pathway of TFs was proposed. TFs mainly underwent dehydrochlorination, cyclization, hydroxylation, etc. to produce a series of nitrogenous heterocyclic compounds that possess higher polarity than parents, hinting that TPs might pose potential aquatic toxicity. However, TPs can be removed synchronously by this tandem technique. The current study can provide a theoretical basis for the harmless treatment of TFs in the water environment.
\end{abstract}

Keywords Photo-electrocatalytic oxidation $\cdot$ Degradation pathway $\cdot$ Triazole fungicides $\cdot$ Synchronous removal $\cdot$ Tandem process

$\begin{array}{ll}\text { Abbreviations } \\ \text { CFD } & \text { Computational fluid dynamics } \\ \text { NCHs } & \text { Nitrogenous heterocyclic compounds } \\ \text { OER } & \text { Oxygen evolution reaction } \\ \text { PECO } & \text { Photo-electrocatalytic oxidation }\end{array}$

Responsible Editor: Vítor Pais Vilar

Xiaoxin Chen

xiaoxinchen518@126.com

Junwen Wang

wjw21030@163.com

Xiaoli Sun

sunxiaoli1997@163.com

Miao Liu

lmhb98@163.com

Xingqiang $\mathrm{Wu}$

xingqiangheda@163.com
PECR Photo-electrocatalytic reactor

$R_{\mathrm{L}} \quad$ Separation factor

SBSE Stir bar sorptive extraction

TFs Triazole fungicides

TPs Transformation products
Yichao Gong

gyichao@126.com

Jianfang Du

djfecn@aliyun.com

1 College of Chemistry and Environmental Science, Hebei University, Baoding City 071002, Hebei Province, China

2 Key Laboratory of Mineral Resources and Eco-environment Monitoring, Hebei Province, Baoding, China

3 Bioengineering Technology Innovation Center of Hebei Province, Baoding, China 


\section{Introduction}

In order to increase the yield and harvest of agricultural products, triazole fungicides (TFs) have been widely used in agricultural production due to the characteristics of low toxicity, high efficiency, and broad spectrum. However, TFs cause different degrees of pollution to rivers, lakes, and groundwater around the world (Climent et al. 2019; Ccanccapa et al. 2016). For example, the average residue of propiconazole in Tengger River Basin in Malaysia is as far as $4493.1 \mathrm{ng} / \mathrm{L}$ (Elfikrie et al. 2020) and approximately $0.291-1.150 \mu \mathrm{g} / \mathrm{L}$ in the soybeangrowing agricultural surface water in south central United States (Battaglin et al. 2011). The residue of tebuconazole in European rivers reaches the level of 175-200 $\mu \mathrm{g} / \mathrm{L}$ (Wang et al. 2011). More and more in vitro and in vivo experiments show that TFs exhibit hepatotoxicity (Zhang et al. 2019), reproductive development toxicity (Tian et al. 2019), and endocrine disruption (Draskau et al. 2019) to non-target organisms. TFs have been listed as one of the "potential carcinogens of human beings" by the U.S. Environmental Protection Agency (USEPA) (Crowell et al. 2011). Although the residues of TFs in the water environment are at the trace level ( $\mathrm{ng} / \mathrm{L}$ or $\mu \mathrm{g} / \mathrm{L}$ ), some TFs such as propiconazole, tebuconazole, and prothioconazole still cause teratogenesis, carcinogenesis, and mutation (Tian et al. 2019; Teng et al. 2019). Therefore, even trace TFs pose a potential threat to the water environment and human health. On the other hand, pesticides are a kind of typical environmental exogenous substances; once they enter into the environment, they will be degraded or metabolized to a series of unknown transformation products (TPs) under the biologic and abiotic actions. Numerous studies indicated that TPs often show stronger polarity, higher persistence, higher bioaccumulation factors, and diverse action pattern than parent itself. It is reported that $51 \%$ of TPs are equally or more toxic than parents, in which the toxicity of $9 \%$ TPs is more than 10 times (Boxall et al. 2004). It is reported that TFs are usually transformed into a series of nitrogenous heterocyclic compounds (NHCs) with unknown chemical properties in the existence of light exposure (Rodríguez-Cabo et al. 2018). However, these existing technologies mainly focus on the degradation of pesticide parent, but little attention is paid to their toxicological TPs (Ying and Luo 2017; Cui et al. 2017), which will inevitably lead to secondary pollution. In view of this, how to achieve synchronous removal and detoxification of TFs and trace toxicological TPs in the water environment becomes an important problem to be solved urgently at present.

As far as we know, the existing degradation technologies of TFs mainly include biochemical process (Wu et al. 2018; Wu et al. 2019), adsorption (Masis-Mora et al. 2019), advanced oxidation processes (AOPs) such as Fenton oxidation (Zhang et al. 2020), photo-catalytic oxidation (Garcia-Muñoz et al. 2020), and electrocatalysis (Cui et al. 2017). At present, the
AOPs have been developed rapidly in degradation of organic pollutants, because of strong oxidation ability, mild reaction conditions, fast reaction rate, and good treatment effect (Zhang et al. 2020; Garcia-Muñoz et al. 2020). Among various AOPs, the photo-electrocatalytic oxidation (PECO) technique fixes the catalyst on a conductive substrate, and the external bias can effectively promote the separation of photo-generated electrons and holes, thus improving the quantum efficiency significantly. Owing to the increase of $\cdot \mathrm{OH}$ on semiconductor surface, PECO exhibits higher catalytic efficiency in degrading organic pollutants than single photocatalysis or electrocatalysis (Wang et al. 2017). Although the PECO technique is described in many papers in literatures, the research on photo-electrocatalytic degradation of TFs is very scarce.

Based on the dispersion state of catalyst, the photoelectrocatalytic reactor (PECR) often includes slurry reactor (Molinari et al. 2017) and immobilized reactor (JaramilloGutiérrez et al. 2020); therein, the former has some shortcomings, such as a complex separation process of the catalyst and lower reusability (Christensen et al. 2003), while the latter can avoid these problems. At present, the most commonly used immobilized PECR is the cylindrical reactor equipped with a ring electrode, which can avoid light energy attenuation due to the distance reduction between the light source and photoanode (Zhao et al. 2014). In addition, mesh electrode is beneficial to enhance mass transfer. Besides, the photoelectrocatalytic efficiency of the tubular reactor can be enhanced by aeration (Suhadolnik et al. 2019). However, the computational fluid dynamics (CFD) showed that there are non-uniform flow and dead volume at the inlet and outlet of the closed tubular reactor (approximately $35 \%$ of the total reactor volume) (Matos et al. 2018). Therefore, we developed a bench-scale submerged reactor with annular network anode on the basis of tubular PECR. Firstly, the designed reactor was in an open state, in which it does not require additional aeration. Secondly, the submerged reactor itself was used as a liquid storage tank that can achieve degradation reaction and water sample storage at the same time, thus reducing the dead volume partly. Besides, the combination of a magnetic stirrer and a circulating pump strengthened the mass transfer.

In order to better understand and guide the harmless treatment of TFs, it is necessary to pay more attention about degradation behavior and transformation pathway when developing a novel treatment technique, because a clear degradation pathway will facilitate the feedback regulation and optimization of process parameters, thus achieving the final goal of green resistance and ecological remediation. However, in order to identify target pollutants accurately and elucidate degradation pathway, there put forward higher requirements about analytical methods because of trace unknown-property TPs. Hence, it is necessary to construct a precise identification system that provides accurate 
information to reflect the degradation behavior and transformation pathway of TFs. As is universally known, the high-resolution chromatography tandem mass spectrometry (HRLC-MS/MS) technique can provide an important support for the accurate quantification of trace compounds in a complex matrix, as well as the structural identification of unknown compounds. Besides, the stir bar sorptive extraction (SBSE) is a simple and efficient pretreatment method with good reproducibility and sensitivity, and there only needs a little liquid samples and organic solvents to extract and enrich ultra-trace compounds from the complex matrix (Aparicio et al. 2017; Ochiai et al. 2013). The combination of SBSE pretreatment and the selected ion detection mode of LC-MS/MS can ensure the limit of detection (LOD) of $\mathrm{ng} / \mathrm{L}$ level (Grau et al. 2019).

The major objectives of this study are as follows: (1) to construct a bench-scale submerged PECR using $\mathrm{IrO}_{2} / \mathrm{RuO}_{2} /$ $\mathrm{TiO}_{2} /$ Ti-based photosensitive mesh electrodes; (2) to clarify the degradation behavior and transformation pathway of TFs at the molecular level on the basis of the SBSE-HRLC-MS/ MS technique; (3) to evaluate the practicability of the PECO$\mathrm{MoS}_{2}$ adsorption technique in the synchronous removal of TFs and their TPs, as well as the potential cancer risk of TFs in effluent to the human body. This study has an important theoretical value and practical significance for green resistance control and ecological restoration of TFs in the water environment.

\section{Materials and methods}

\section{Chemicals and instruments}

The standards of diniconazole (99.0\%) and propiconazole (99.0\%) were purchased from Beijing Qincheng Yixin Technology Development Co., Ltd. (Beijing, China). Tetraconazole standard (98.8\%), HPLC-grade acetonitrile, methanol, and formic acid were purchased from J\&K Scientific Ltd. (Beijing, China). The analytical-grade reagents in the experiments were obtained from Aladdin Reagent Co., Ltd. (Shanghai, China). Ultra-pure water was supplied by a local supermarket. $\mathrm{MoS}_{2}$ and $\mathrm{WS}_{2}$ nanoparticles were obtained from Guangdong Mitak Metal Materials Co., Ltd. (Guangzhou, China). The Nylon microfilter $(0.22 \mu \mathrm{m})$ was provided by Peak Sharp Company, P. R. China. The bipolar ACAR/PDMS stir bar (ZZ-SBSE-2-01, $20 \mathrm{~mm}$ length $\times$ $1.0 \mathrm{~mm}$ thickness) was provided by Qingdao Zhenzheng Analytical Instrument Co., Ltd. (Qingdao, China). The acetic acid-sodium acetate buffer solution $(\mathrm{pH} 4.0)$ was prepared with $3.6 \mathrm{~mL}$ sodium acetate solution $(1.0 \mathrm{~mol} / \mathrm{L})$ and 16.4 $\mathrm{mL}$ acetic acid solution $(1.0 \mathrm{~mol} / \mathrm{L})$. Standard stock solutions of individual diniconazole $(5000 \mathrm{mg} / \mathrm{L})$, propiconazole $(9830$ $\mathrm{mg} / \mathrm{L})$, and tetraconazole $(1976 \mathrm{mg} / \mathrm{L})$ were prepared using
HPLC-grade acetonitrile in a brown volumetric flask, respectively. The standard solutions were stored at $-20^{\circ} \mathrm{C}$ to maintain stability within 1 year. The intermediate standard mixture solution $(50 \mathrm{mg} / \mathrm{L})$ of propiconazole (PRO), tetraconazole (TET), and diniconazole (DIN) was prepared by diluting stock solutions with HPLC-grade acetonitrile. The individual working aqueous solutions $(1.0 \mathrm{mg} / \mathrm{L})$ of PRO, TET, and DIN and the mixed working solutions $(1.0 \mathrm{mg} / \mathrm{L})$ of three pesticides were prepared with deionized water, respectively, according to the following method. An appropriate amount stock solution was pipetted and transformed into a $100-\mathrm{mL}$ flask, and solvent evaporation was performed by an evaporator under 40 ${ }^{\circ} \mathrm{C}$ water bath. Finally, the target pesticides were reconstituted with $2.0 \mathrm{~L}$ deionized water by ultrasound using ethanol $\left(0.05 \%\right.$, v:v) as a cosolvent. $\mathrm{IrO}_{2} / \mathrm{RuO}_{2} / \mathrm{TiO}_{2} /$ Ti-based photosensitive coating mesh electrodes (cylindrical anode $24 \mathrm{~cm}$ length $\times 4 \mathrm{~cm}$ i.d., rhombus mesh density of $4 \mathrm{~cm}^{-2}$; rectangular sheet cathode $24 \mathrm{~cm}$ length $\times 4 \mathrm{~cm}$ width, rhombus mesh density of $4 \mathrm{~cm}^{-2}$ ) were customized by Mingxuan Titanium Products Co., Ltd (Xingtai, Hebei). The tank of bench-scale submerged PECR $(28 \mathrm{~cm}$ length $\times 12 \mathrm{~cm}$ width $\times 10 \mathrm{~cm}$ height, thickness $1.0 \mathrm{~cm}$, side hole diameter $35 \mathrm{~mm}, 2.5 \mathrm{~L}$ ) was provided by Shanghai Acrylic Co., Ltd. (Shanghai, China). A rotary evaporator (RV 10 digital, IKA (Guangzhou) Instrument Equipment Co., Ltd.) was used to evaporate solvent. For the quantification of TFs and identification of TPs in aqueous solution, a high-performance liquid chromatography (LC-20AT, Shimadzu) tandem triple quadrupole mass spectrometer (ABS Triple Quad 5500, USA) (HPLC-QqQ-MS/MS) equipped with a reversed-phase C18 column $(100 \mathrm{~mm} \times 4.6$ I.D., $5 \mu \mathrm{m}$, Kromat Corporation $)$ and a Dual JetSpray electrospray ionization source in the positive ion mode $\left(\mathrm{ESI}^{+}\right)$was employed in this study.

\section{Stir bar sorptive extraction pretreatment}

To enrich the trace TPs, the SBSE pretreatment method was used in this study as the following procedure. The ACAR/ PDMS stir bar was preconditioned with $1.0 \mathrm{~mL}$ methanol by ultrasound for $20 \mathrm{~min}$ and dried at $70{ }^{\circ} \mathrm{C}$. The liquid sample $(2.0 \mathrm{~mL})$ was transferred to a $50-\mathrm{mL}$ glass beaker. Subsequently, the $\mathrm{pH}$ was adjusted to 4 with acetic acidsodium acetate buffer solution. After the preactivated stir bar was put into the buffer solution system, the solution was stirred magnetically at $600 \mathrm{rpm}$ for $40 \mathrm{~min}$, to extract target pollutants from water samples. Afterwards, the stir bar was placed into another extraction flask adding into $500 \mu \mathrm{L}$ methanol-acetonitrile mixture $(1: 1, \mathrm{v}: \mathrm{v})$, and the target analytes were desorbed for 20 min by ultrasound. Finally, the extract was filtered through a $0.22-\mu \mathrm{m}$ fiber prior to LCMS/MS analysis. Three parallel treatments were performed for each. 


\section{PECR construction}

A well-designed reactor can increase the degradation rates of TFs. In this study, a bench-scale PECR $(280 \mathrm{~mm}$ length, $12 \mathrm{~mm}$ width, $10 \mathrm{~mm}$ depth, plexiglass material) was designed and constructed as shown in Fig. S1. An ultraviolet lamp radiating $254 \mathrm{~nm}$ wavelength was matched with ballast and quartz lamp sleeve, and $30 \mathrm{~mW} / \mathrm{cm}^{2}$ and $50 \mathrm{~mW} / \mathrm{cm}^{2}$ was set for degradation of TFs, respectively. The lamp device was used as the inner light source of the reactor in immersion mode. The mesh cylinder anode was covered outside the light source, while the mesh sheet cathode was placed vertically in the solution. The anode and cathode were connected to the direct-current power. The reactor was placed onto a multichannel magnetic stirrer (SP200-2T, Hangzhou Miou Instrument Co., Ltd, China). Meanwhile, a small circulating pump (flow rate of $2.0 \mathrm{~L} / \mathrm{min}$ ) was connected to the reactor with a silica gel tube to enhance mass transfer.

\section{Photo-electrocatalytic degradation of TFs}

\section{Parameter optimization}

The $\mathrm{Na}_{2} \mathrm{SO}_{4}$ was used as the electrolyte in the process of photoelectrocatalysis. The aqueous solution of TFs $\left(C_{0}=1.0 \mathrm{mg} / \mathrm{L}\right.$, $0.05 \mathrm{~mol} / \mathrm{L} \mathrm{Na}_{2} \mathrm{SO}_{4}, 2.0 \mathrm{~L}$ ) was investigated under different operation parameters of reactor. The effects of bias voltage $(1.8,2.0,2.5$, and $3.0 \mathrm{~V})$, irradiation intensity $\left(30 \mathrm{~mW} / \mathrm{cm}^{2}\right.$ or $\left.50 \mathrm{~mW} / \mathrm{cm}^{2}\right)$, initial concentration $\left(C_{0}=1.0,5.0\right.$, and $\left.20 \mathrm{mg} / \mathrm{L}\right)$, $\mathrm{pH}(4,7$, and 9), and iron ion ( $\mathrm{Fe}(\mathrm{II}), 0-2.0 \mathrm{mg} / \mathrm{L})$ on degradation rates of were investigated. The ferrous sulfate $\mathrm{Fe}(\mathrm{II})$ with different amounts was added into the mixture $\left(C_{0}=1.0 \mathrm{mg} / \mathrm{L}\right)$ of PRO, TET, and DIN. The $\mathrm{pH}$ values of aqueous solutions were adjusted to 4, 7, or 9 with dilute sulfuric acid or sodium hydroxide solution. Sampling $(2.0 \mathrm{~mL})$ was performed at the intervals and pretreated according to the above procedure in "Stir bar sorptive extraction (SBSE) pre-treatment." Finally, the residues of target compounds were analyzed in the multiple reaction monitoring (MRM) mode of the HPLC-MS/MS technique after filtered by a $0.22-\mu \mathrm{m}$ filter membrane. The mobile phase was the mixture of acetonitrile (A) and $0.2 \%$ formic acid aqueous solution (B) $(80: 20, \mathrm{v}: \mathrm{v})$ with the flow rate of $0.2 \mathrm{~mL} / \mathrm{min}$. The column temperature was controlled at $30^{\circ} \mathrm{C}$. The injection volume was $1.0 \mu \mathrm{L}$. The mass spectrometry parameters were as follows. The ion source temperature was controlled at $200{ }^{\circ} \mathrm{C}$. The flow rate and pressure of nebulizer gas $\left(\mathrm{N}_{2}, 450^{\circ} \mathrm{C}\right)$ were 11 $\mathrm{L} / \mathrm{min}$ and $40 \mathrm{psi}$, respectively. The capillary voltage was 4000 $\mathrm{V}$. The fragment voltage was $120 \mathrm{~V}$ for TET and $100 \mathrm{~V}$ for both PRO and DIN, respectively. The selected quantitative (qualitative) ion pairs for PRO were 342.1/159.1 (342.1/70) and 372/159 (372/185) for TET and 326.1/70 (326.1/158.7) for DIN. The mass data acquisition was performed by the Multi Quant Workstation Software (version 3.0).

\section{TP identification}

The individual aqueous solutions of PRO, TET, and DIN $\left(C_{0}\right.$ $=1.0 \mathrm{mg} / \mathrm{L}, 0.05 \mathrm{~mol} / \mathrm{L} \mathrm{Na}_{2} \mathrm{SO}_{4}, 2.0 \mathrm{~L}$ ) were degraded for 30 , 30 , and $15 \mathrm{~min}$, respectively. Samples $(2.0 \mathrm{~mL})$ were collected and pretreated according to the procedure in "Stir bar sorptive extraction (SBSE) pre-treatment." These TPs were analyzed in a scan mode of HPLC-MS/MS with the range of $m / z 100$ 450 , and the PI mode was used to obtain adequate mass spectrometry data from a mass analyzer. The mobile phase was the mixture of acetonitrile (A) and $0.2 \%$ formic acid aqueous solution (B) with the volume ratio of 60:40 (PRO), 60:40 (TET), and 50:50 (DIN). The flow rate was $0.4 \mathrm{~mL} / \mathrm{min}$. The stop time was $30 \mathrm{~min}$. The column temperature was controlled at $30^{\circ} \mathrm{C}$. The injection volume was $20 \mu \mathrm{L}$ for PRO (or TET) and $25 \mu \mathrm{L}$ for DIN. The ion source temperature was controlled at $450{ }^{\circ} \mathrm{C}$. The $\mathrm{ESI}^{+}$was operated. The column temperature was controlled at $35^{\circ} \mathrm{C}$. The $40-\mathrm{psi} \mathrm{N}_{2}$ was used as a nebulizer. The flow rates for drying gas $\left(325^{\circ} \mathrm{C}\right)$ and sheath gas $\left(325^{\circ} \mathrm{C}\right)$ were $10 \mathrm{~L} / \mathrm{min}$ and $11 \mathrm{~L} / \mathrm{min}$, respectively. The capillary voltage was controlled at $4000 \mathrm{~V}$.

\section{Adsorption of TFs and TPs by nano-MoS 2}

\section{Optimization of adsorption conditions}

To obtain optimum adsorption effects of TF parent and their TPs, the PRO aqueous solution $\left(C_{0}=1.0 \mathrm{mg} / \mathrm{L}\right)$ was firstly degraded for $60 \mathrm{~min}$ by the reactor device. Subsequently, the primary effluent was used to optimize the adsorption process. The major operation parameters including dosages of $\mathrm{MoS}_{2}$ or $\mathrm{WS}_{2}$, initial concentration $\left(C_{0}\right), \mathrm{pH}$, adsorption temperature, and stirring speed were optimized in this study. The dark control was performed under the light-free condition with tinfoil wrapping. The samples were collected at the intervals of 0 , $1,2,5,10,15,20$, and $30 \mathrm{~min}$ and pretreated according to the SBSE pretreatment method. The residues of PRO and their TPs were analyzed via the HPLC-MS/MS technique after filtered by a $0.22-\mu \mathrm{m}$ filter as described in "Stir bar sorptive extraction (SBSE) pre-treatment." In order to verify the actual removal effect of optimum adsorption unit to TFs and their TPs, the mixed aqueous solution of PRO, TET, and DIN $\left(C_{0}=\right.$ $1.0 \mathrm{mg} / \mathrm{L}$ ) was firstly degraded for $30 \mathrm{~min}$. Subsequently, the target pollutants in primary effluent were adsorbed under the optimum adsorption conditions.

\section{Adsorption capacity of $\mathrm{MoS}_{2}$}

The adsorption effects of $\mathrm{MoS}_{2}$ to TFs can be estimated via separation factor $\left(R_{\mathrm{L}}\right)$ because it is related to the surface activation energy of adsorbent. The adsorption will be easy under experimental conditions when $R_{\mathrm{L}}$ is in the range of $0-1$. The lower $R_{\mathrm{L}}$ facilitates the adsorption of $\mathrm{MoS}_{2}$ to TFs. Firstly, 
the Langmuir adsorption isotherm equation was plotted by the regression analysis of $C / Q$ versus $C$ according to Formula (2). Subsequently, $R_{\mathrm{L}}$ was calculated according to Formula (3).

$Q=\frac{\left(C_{0}-C\right) \times V}{m}$

$\frac{C}{Q}=\frac{1}{Q_{\mathrm{e}}} \times C+\frac{1}{Q_{e} \times b}$

$R_{L}=\frac{1}{1+b \times C_{0}}$

where $C_{0}$ and $C$ are the initial and equilibrium concentration $(\mathrm{mg} / \mathrm{L})$ of pollutants in water phase, respectively. The $m$ was the dosage of $\mathrm{MoS}_{2}$. The variable $V$ was the volume (L) of water sample. $Q$ and $Q_{\mathrm{e}}$ were the isotherm adsorption capacity $(\mathrm{mg} / \mathrm{g})$ and the saturated adsorption capacity $(\mathrm{mg} / \mathrm{g})$, respectively. The parameter $b$ was the adsorption equilibrium constant.

\section{Practicability of the PECO-MoS 2 adsorption technique}

The actual surface water was firstly pretreated by a $0.45-\mu \mathrm{m}$ water microfilter to remove particulate impurities. Then, the filtrate was spiked with the standard mixture solution of PRO, TET, and DIN to obtain the simulated water samples $(1.0 \mathrm{mg} /$ L). Firstly, the water samples were treated for $30 \mathrm{~min}$ via the established reactor. Subsequently, the primary effluent (100 $\mathrm{mL}$ ) was treated under the optimum adsorption process to remove TF parents and their TPs synchronously. The degradation rate of target pollutants was evaluated on the basis of dynamic data. Meanwhile, the total organic carbon (TOC) was detected by a TOC analyzer. These samples were pretreated in triplicate for each.

\section{Carcinogenic risk assessment of effluent}

It is necessary to predict the potential cancer risk of effluent to the human body, because it will further guide the process improvement. In this study, the carcinogenic risk coefficient $(P)$ of individual TFs in effluent was evaluated on the basis of the residual concentration $(C)$. The adult average weight $(65$ $\mathrm{kg}$ ) and daily water intake (2.0 L/day) were used for risk assessment as the following formula.

$P=\frac{C(\mathrm{mg} / \mathrm{L}) \times 10^{-6} \times 2.0 \mathrm{~L}}{65 \mathrm{~kg}} \times f$

According to USEPA-2008, the control standard of carcinogenic risk induced by drinking water containing chemical pollutants should be in the range of $10^{-6}-10^{-4}$. In view of the maximum risk principle, $10^{-6}$ was referenced as the safe drinking standard in this study. Moreover, 1.0 was considered the carcinogenic potency factor $(f)$ of target analyte in order to improve the process based on the most stringent standard.

\section{Results and discussions}

\section{Photo-electrocatalysis kinetics of typical TFs}

The effects of bias voltage, initial concentration $\left(C_{0}\right)$, irradiation intensity, $\mathrm{pH}$ values, and $\mathrm{Fe}(\mathrm{II})$ on degradation rates of PRO, TET, and DIN were investigated. As shown in Fig. 1a, the rate constants of photo-electrocatalysis and photodegradation of PRO were $0.0162 \mathrm{~min}^{-1}\left(R^{2}=0.9861\right)$ and $0.0087 \mathrm{~min}^{-1}\left(R^{2}=0.9982\right)$, respectively, indicating that the photo-electrocatalytic efficiency was higher than that of single photo-degradation under the same conditions. As shown in Fig. 1b, a downward trend about the degradation rates of PRO was observed with the increase of bias voltage (1.8-3.0 V). This result was mainly attributed to the competitive oxygen evolution reaction (OER) induced by water electrolysis, because some bubbles were escaped from the anode surfaces, and there were more and more bubbles with the increasing bias voltage $(>2.0 \mathrm{~V})$. This viewpoint was supported by the published literature (Li et al. 2000). Although the increase of bias voltage was conducive to the degradation of organic pollutants to a certain extent, the higher bias voltage (beyond oxygen evolution potential) not only makes water electrolysis the main reaction on the electrode, but also causes serious anode pollution (Rodgers and Bunce 2001). We found that the electrocatalytic removal rate of PRO began to decline when the voltage exceeded $2.0 \mathrm{~V}$ (Fig. 1c). This result further confirmed that the applied bias voltage should be below $2.0 \mathrm{~V}$ under the experimental conditions in this study. On the other hand, Fig. $1 \mathrm{~b}$ indicates that the electric current was basically unchanged with degradation time under the constant voltage $(1.8 \mathrm{~V}$ or $2.0 \mathrm{~V})$. This result suggested that the number and rate of photo-generated electrons moving to the opposite electrode remain unchanged during the photo-electrocatalytic degradation process. In other words, the photo-electrocatalytic effect was basically unchanged under the bias voltage of $1.8 \mathrm{~V}$ or $2.0 \mathrm{~V}$. Furthermore, the degradation rates of PRO $\left(C_{0}=5.0 \mathrm{mg} / \mathrm{L}, 0.05 \mathrm{~mol} / \mathrm{L} \mathrm{Na}_{2} \mathrm{SO}_{4}\right)$ were $65.0 \%(1.8 \mathrm{~V})$ and $61.3 \%(2.0 \mathrm{~V})$, respectively, under 60 -min photoelectrocatalysis. Considering the above-mentioned reasons comprehensively, $1.8 \mathrm{~V}$ was applied to the photosensitive electrodes for the degradation of TFs. Figure 1d indicates that the higher irradiation intensity contributed to the degradation of pollutants. As seen from Fig. 1e, the photo-electrocatalytic degradation of PRO was well in line with the first-order kinetics $\left(R^{2}>0.9938\right)$. The rate constants were $0.0334 \mathrm{~min}^{-1}$ $(1.0 \mathrm{mg} / \mathrm{L}), 0.0315 \mathrm{~min}^{-1}(5.0 \mathrm{mg} / \mathrm{L})$, and $0.0099 \mathrm{~min}^{-1}(20$ $\mathrm{mg} / \mathrm{L}$ ), respectively. The lower rate constant at a lower initial concentration might be mainly depended on the number of 

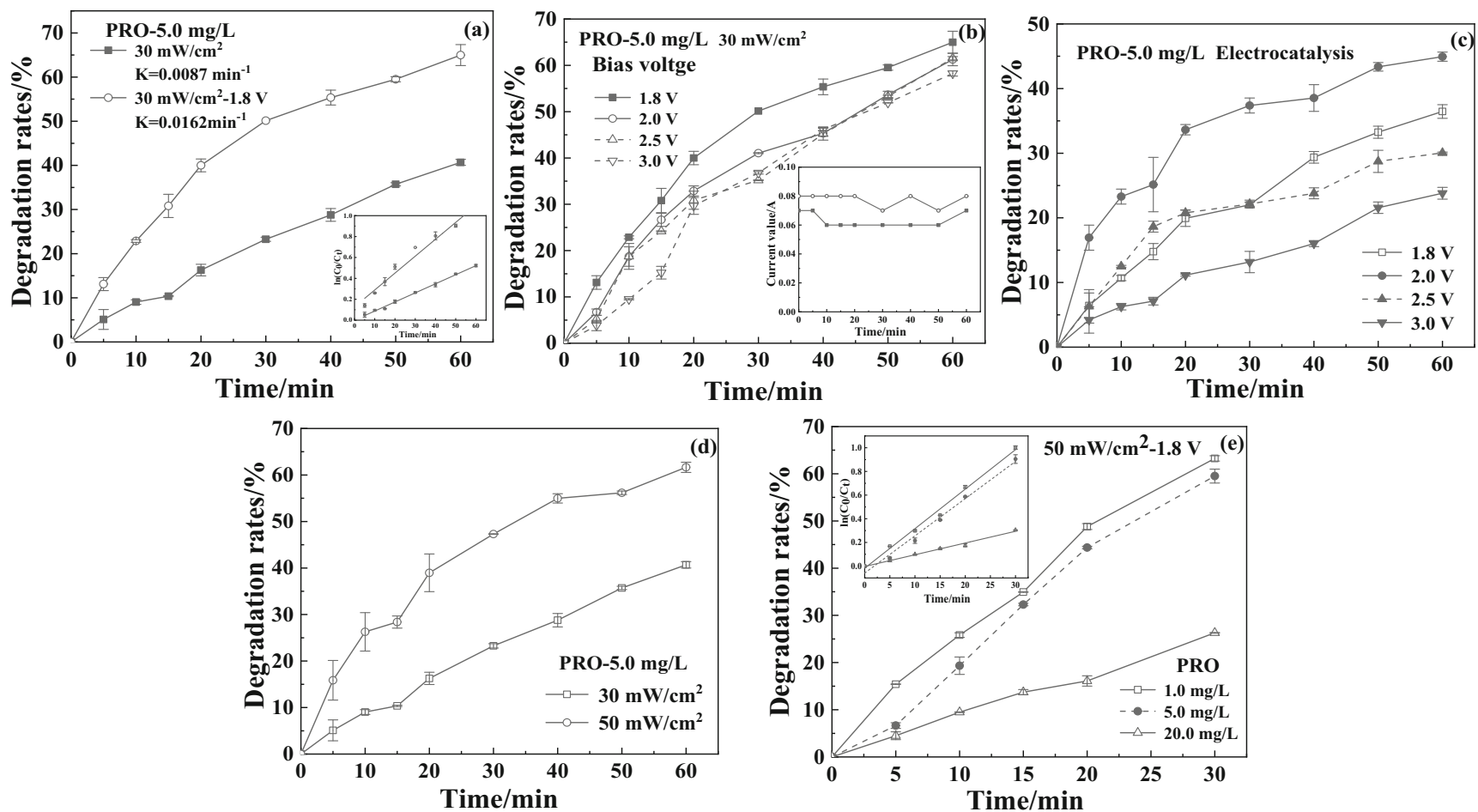

Fig. 1 Effects of bias voltage $(\mathbf{a}, \mathbf{b})$, electrocatalytic voltage $(\mathbf{c})$, light intensity $(\mathbf{d})$, and initial concentration $(\mathbf{e})$ on degradation rates of PRO in aqueous solution $\left(0.05 \mathrm{~mol} / \mathrm{L} \mathrm{Na}_{2} \mathrm{SO}_{4}\right)$

active sites on electrode surface. However, it is worth noting that although the decomposition was faster at lower concentrations, the removal amounts of TFs were higher at greater concentrations.

The effects of $\mathrm{pH}$ and $\mathrm{Fe}$ (II) on degradation kinetics of DIN, TET, and PRO in aqueous solution are described in Fig. S2(a-f). Fig. S2(a) indicated that DIN was easily degraded in acid, neutral, or alkaline media without meeting the firstorder kinetics, and the degradation rates of DIN $\left(C_{0}=1.0 \mathrm{mg} /\right.$ L) within 5 min were up to $95.84 \%(\mathrm{pH}=4), 91.01 \%(\mathrm{pH}=7)$, and $94.38 \%(\mathrm{pH}=9)$, respectively. Almost no degradation of DIN was observed after $5 \mathrm{~min}$. However, the photoelectrocatalysis degradation of PRO and TET in aqueous solutions followed pseudo-first-order kinetics remarkably, with satisfactory linear relations of $\ln \left(C_{t} / C_{0}\right)$ versus time $(t)\left(R^{2}\right.$, 0.9768-0.9930) (Fig. S2(b, c)). It was easily observed from the curve slopes that the degradation rates of both PRO and TET in acidic medium were higher than that of alkaline. As a kind of weak acid pesticide, TFs in acid medium mainly existed in the molecular form, in which it was easily adsorbed on the electrode surface; thus, photo-electrocatalysis was favorable. Besides, the theoretical redox potentials of $\cdot \mathrm{OH} / \mathrm{H}_{2} \mathrm{O}$ based on the Nernst equation were $2.354 \mathrm{~V}(\mathrm{pH} 4), 2.177 \mathrm{~V}$ (pH 7), and $2.059 \mathrm{~V}(\mathrm{pH} 9)$, respectively (Table S1). These data also showed that acidic medium was beneficial to the degradation of TFs (Mazierski et al. 2019). An accelerating effect as to the degradation of PRO and TET was observed with the presence of $\mathrm{Fe}(\mathrm{II})$ in the range of $0.1-2.0 \mathrm{mg} / \mathrm{L}$ (Fig.
$\mathrm{S} 2(\mathrm{e}, \mathrm{f})$ ), because $\mathrm{Fe}(\mathrm{II})$ mainly exists in aqueous solution in the dissolved forms of $\mathrm{Fe}^{2+}, \mathrm{Fe}^{2+}, \mathrm{FeOH}^{2+}$, and $\mathrm{Fe}_{2}(\mathrm{OH})_{2}{ }^{4+}$, in which $\mathrm{FeOH}^{2+}$ could be photo-active to the decay of PRO and TET due to the photo-generated hydroxyl radicals (Chen et al. 2016). However, this photosensitization was almost not reflected in DIN degradation (Fig. S2(d)), which might be due to the rapid degradation rate.

\section{Transformation pathway of TFs}

The major TPs of three typical TFs (PRO, TET, and DIN) were identified on the basis of the accurate MS/MS data (their protonated molecules, MS/MS fragmentation patterns, and reasonable fragment loss regulations) (Tables $\mathrm{S} 2-\mathrm{S} 4$ and Figs. 2, 3, and 4). As shown in Table S2 and Fig. 2, there generated ten byproducts with PRO photo-electrocatalysis degradation. PRO-TPs306A was derived from cyclized dehydrochlorination of PRO parent, and it included the characteristic fragments of 238 and 220 corresponding to the loss of $\mathrm{C}_{5} \mathrm{H}_{8}$ and $\left(\mathrm{C}_{5} \mathrm{H}_{8}+\mathrm{H}_{2} \mathrm{O}\right)$, respectively. The two ether bonds of PRO-TPs306A were further hydrolyzed to form PROTPs238A with two $\mathrm{H}_{2} \mathrm{O}$ losses. However, PRO-TPs238B was generated from the ether bond hydrolysis of the PRO parent along with two $\mathrm{H}_{2} \mathrm{O}$ eliminations. Although PROTPs238A and PRO-TPs238B exhibited the same characteristic fragment of $m / z, 220$, they represented the loss of $\mathrm{H}_{2} \mathrm{O}$ molecule and hydroxylation of chlorine atom, respectively. Owing to higher polarity of two hydroxyl groups, PRO- 
Fig. 2 TPs of PRO in aqueous solution and transformation pathway

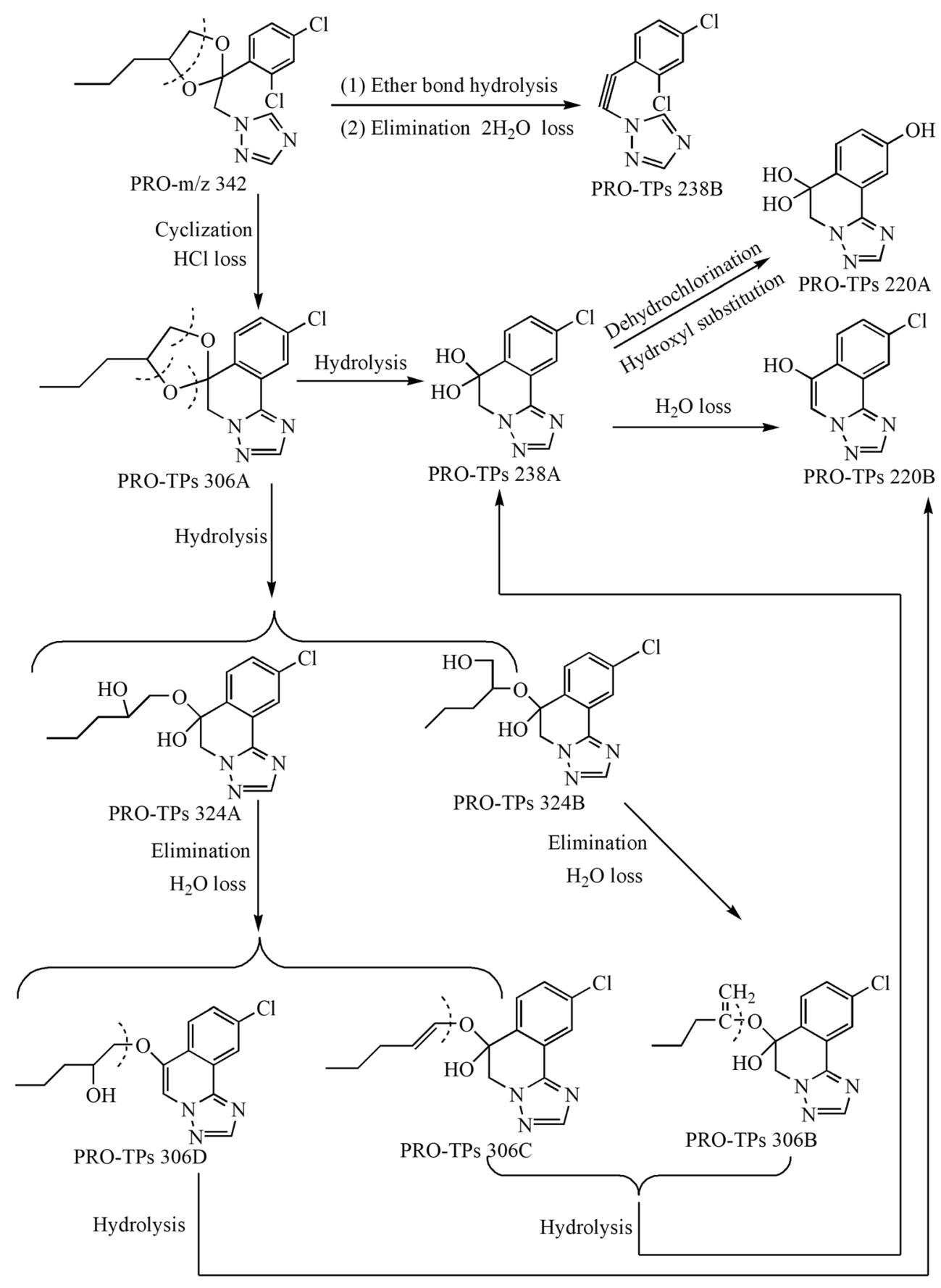

TPs238A $\left(R_{\mathrm{t}}=2.0 \mathrm{~min}\right)$ was eluted preferably in the $\mathrm{C} 18$ reversed-phase column than PRO-TPs238B $\left(R_{\mathrm{t}}=4.0 \mathrm{~min}\right)$. The substitution of chlorine atom by the hydroxyl group on the benzene ring of PRO-TPs238A caused the formation of PRO-TPs220A, while underwent the elimination of $\mathrm{H}_{2} \mathrm{O}$ molecule to form PRO-TPs220B. The reasonable fragmentation loss patterns were beneficial for verifying the molecular structure of PRO-TPs220A and PRO-TPs220B (Table S2). Both PRO-TPs324A and PRO-TPs324B came from the hydrolysis of ether bond of PRO-TPs306A. PRO-TPs324A showed the fragments of $m / z 306,283,265,255$, and 238, representing the loss of $\mathrm{H}_{2} \mathrm{O},\left(\mathrm{C}_{3} \mathrm{H}_{5}\right),\left(\mathrm{C}_{3} \mathrm{H}_{5}+\mathrm{H}_{2} \mathrm{O}\right),\left(\mathrm{C}_{3} \mathrm{H}_{5}+\mathrm{CO}\right)$, and $\left(\mathrm{C}_{3} \mathrm{H}_{5}+\right.$ $\left.\mathrm{H}_{2} \mathrm{O}+\mathrm{C}_{2} \mathrm{H}_{3}\right)$, respectively. The characteristic ions $(\mathrm{m} / \mathrm{z}, 306$, 238, and 220) of PRO-TPs324B corresponded to the neutral loss of $\mathrm{H}_{2} \mathrm{O},\left(\mathrm{H}_{2} \mathrm{O}+\mathrm{C}_{5} \mathrm{H}_{8}\right)$, and $\left(\mathrm{H}_{2} \mathrm{O}+\mathrm{C}_{5} \mathrm{H}_{8}+\mathrm{H}_{2} \mathrm{O}\right)$, respectively. PRO-TPs306B, PRO-TPs306C, and PRO-TPs306D were hydrolysates of PRO-TPs324. In addition, the former two might be hydrolyzed to form PRO-TPs238A, while PRO-TPs306D produced PRO-TPs220B with hydrolysis. As shown in Table S3 and Fig. 3, there formed four TPs with DIN photo-degradation. DIN parent $\left([\mathrm{M}+\mathrm{H}]^{+}, m / z\right.$ 326) went through cyclization directly with dehydrochlorination to 
Fig. 3 TPs of DIN in aqueous solution and transformation pathway<smiles>CC(C)(C)Cc1cc2ccc(Cl)cc2c2ncnn12</smiles>

DIN-TPs 290C

DIN-TPs 290B

DIN-TPs 274 produce DIN-TPs290C with the molecular formula $\mathrm{C}_{15} \mathrm{H}_{16} \mathrm{ClN}_{3}$. DIN was firstly isomerized, following the cyclization and hydroxyl oxidation to produce DIN-TPs290B, while generating DIN-TPs290A due to subsequent cyclization and dehydrochlorination. The structures of three isomers were corroborated by the characteristic fragment ions. DIN-TPs274 was derived from DIN-TPs 290A with hydroxyl loss. Compared with previous studies (Masis-Mora et al. 2019), there was a slight difference in these degradation products. As shown in Table S4 and Fig. 4, there were two major cyclization products due to the photo-degradation of TET. TET-TPs335 with the molecular formula of $\mathrm{C}_{13} \mathrm{H}_{10} \mathrm{ClF}_{4} \mathrm{~N}_{3} \mathrm{O}$ came from the cyclized dehydrochlorination of TET parent, and it showed two characteristic ions $(\mathrm{m} / \mathrm{z} 218.0$ and 204.1) corresponding to the loss of $\mathrm{C}_{2} \mathrm{HF}_{4} \mathrm{O}$ and side chain, respectively. TET-TPs 206 was generated from the side-chain oxidation of the TET parent molecule, simultaneous with the fragment loss of $\mathrm{m} / \mathrm{z} 170.3(\mathrm{HCl}), \mathrm{m} / \mathrm{z}$ $164.1\left(\mathrm{C}_{2} \mathrm{H}_{4} \mathrm{~N}\right)$, and $m / z, 102.0\left(\mathrm{C}_{2} \mathrm{H}_{2} \mathrm{~N}_{3}\right)$.

In short, three typical TFs underwent cyclization and dichlorination to form a series of nitrogenous heterocyclic compounds (NCHs), and these TPs exhibited higher polarity than parent itself. This result implied that TPs may be more toxic to aquatic organisms than parent to some extent, because they are easier to migrate to aquatic system by rain wash or soil leaching. Therefore, it is extremely necessary to focus on both TPs and parent compounds when a new treatment technology is developed.

\section{Optimal adsorption process}

To determine the optimal dosages of $\mathrm{MoS}_{2}$ and $\mathrm{WS}_{2}$ on PRO aqueous solution $\left(100 \mathrm{~mL}, C_{0}=1.0 \mathrm{mg} / \mathrm{L}\right)$, the adsorption rates were investigated at the room temperature as shown in Fig. 5a. The results indicated that $\mathrm{MoS}_{2}$ exhibited a slightly better adsorption effect than $\mathrm{WS}_{2}$ in the range of $<0.08 \mathrm{~g} / 100 \mathrm{~mL}$ aqueous solution, and no obvious increase in adsorption rate was observed when the dosage of $\mathrm{MoS}_{2}$ exceeded $0.05 \mathrm{~g}$ per $100 \mathrm{~mL}$ aqueous solution. Hence, the dosage of $0.05 \mathrm{~g} \mathrm{MoS}_{2} /$ $100 \mathrm{~mL}$ solution $\left(C_{0}=1.0 \mathrm{mg} / \mathrm{L}\right)$ was used to optimize the parameters of adsorption process unit. The effects of initial concentration, $\mathrm{pH}$ value, agitation speed, and temperature on PRO removal rates were investigated. Firstly, PRO aqueous solution $\left(C_{0}=1.0 \mathrm{mg} / \mathrm{L}\right)$ was degraded for $30 \mathrm{~min}$ via the bench-scale photo-electrocatalytic reactor under the optimal conditions. Subsequently, the primary effluent $(100 \mathrm{~mL})$ was used to optimize the process parameters of secondary adsorption unit. As shown in Fig. 5b, the adsorption of $\mathrm{MoS}_{2}$ to PRO $(0.5-5.0 \mathrm{mg} / \mathrm{L})$ was almost saturated within $5 \mathrm{~min}$ for different initial concentrations, and PRO were removed from 5.0 to 2.87 $\mathrm{mg} / \mathrm{L}$, from 2.0 to $0.643 \mathrm{mg} / \mathrm{L}$, from 1.00 to $0.254 \mathrm{mg} / \mathrm{L}$, and
Fig. 4 TPs of TET in aqueous solution and transformation pathway

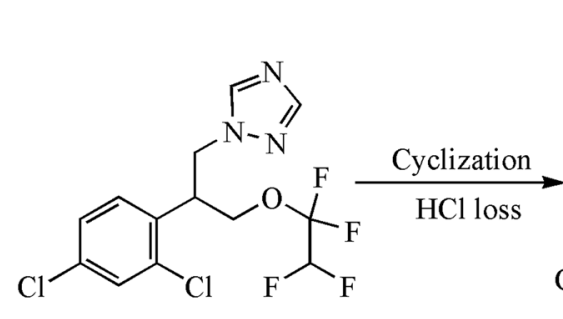

TET-m/z 372<smiles>FC(F)C(F)(F)OCC1Cn2ncnc2-c2cc(Cl)ccc21</smiles>

TET-TPs 206 

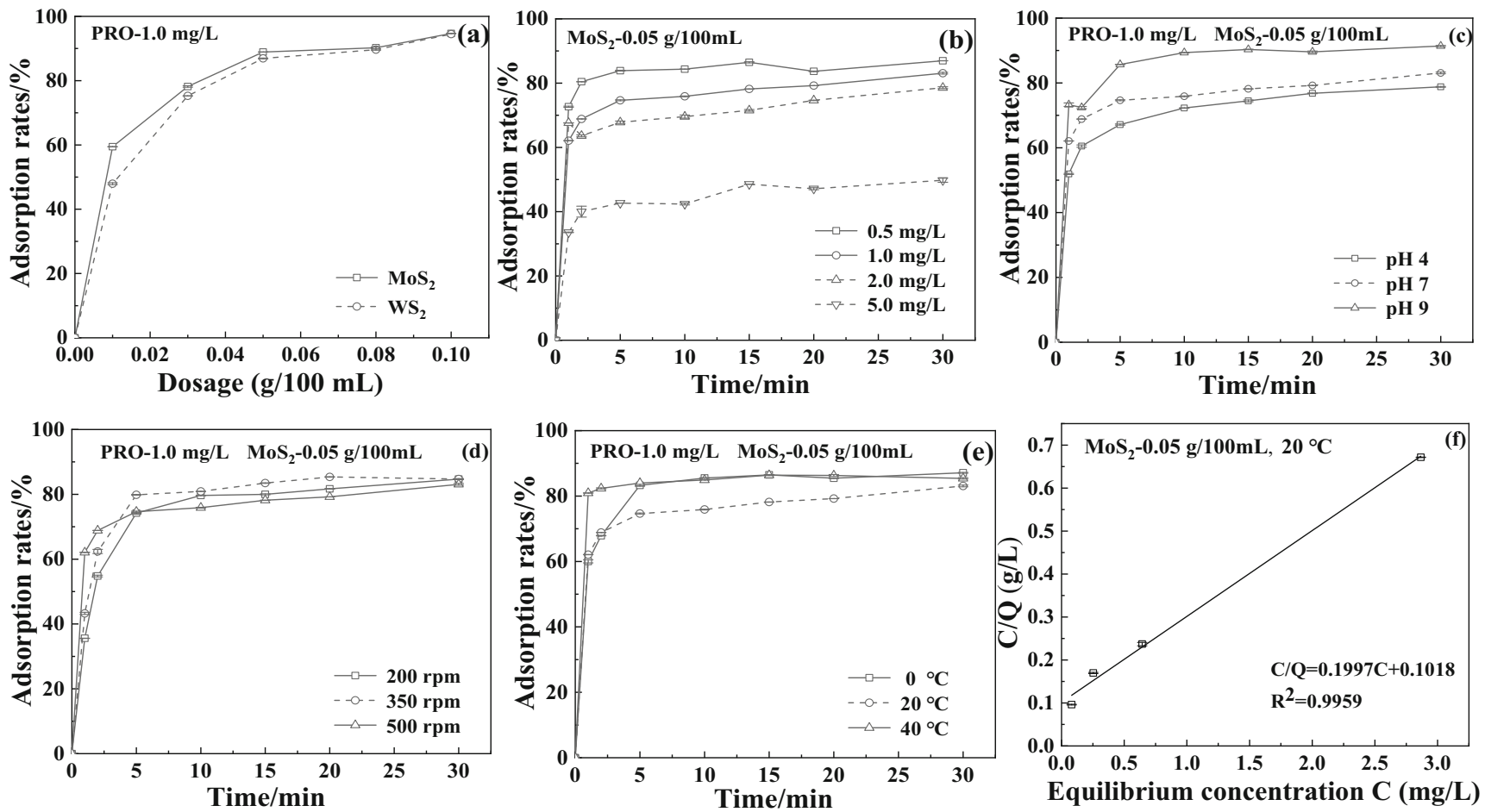

Fig. 5 Optimization of the nano- $\mathrm{MoS}_{2}$ adsorption unit (PRO, $1.0 \mathrm{mg} / \mathrm{L}$ )

from 0.5 to $0.081 \mathrm{mg} / \mathrm{L}$, respectively. Obviously, the higher the initial PRO concentration was, the easier it was adsorbed by $\mathrm{MoS}_{2}$. This result might be interpreted by the separation factor $\left(R_{\mathrm{L}}\right)$ of $\mathrm{MoS}_{2}$. The $R_{\mathrm{L}}$ values at different initial concentrations of PRO were calculated as the results of $0.5048(0.5$ $\mathrm{mg} / \mathrm{L}), 0.3376(1.0 \mathrm{mg} / \mathrm{L}), 0.2031(2.0 \mathrm{mg} / \mathrm{L})$, and $0.0925(5.0$ $\mathrm{mg} / \mathrm{L})$ on the basis of the slope $(0.1997)$ and intercept $(0.1018)$ of the isotherm adsorption equation $\left(R^{2}=0.9959\right)$ (Fig. $5 \mathrm{f}$ ). There appeared a downward trend in $R_{\mathrm{L}}$ values with increasing initial concentrations of PRO, indicating that there was more conducive to adsorption of PRO. As shown in Fig. 5c, the adsorption rates of PRO $\left(C_{0}=1.0 \mathrm{mg} / \mathrm{L}, 0.05 \mathrm{~g} \mathrm{MoS}_{2} / 100\right.$ $\mathrm{mL})$ were $72.3 \%(\mathrm{pH} 4), 75.9 \%(\mathrm{pH} 7)$, and $89.4 \%(\mathrm{pH} 9)$ within $10 \mathrm{~min}$, respectively, indicating that the higher $\mathrm{pH}$ value was beneficial to the adsorption of $\mathrm{MoS}_{2}$ to PRO. The lower adsorption rate in acid medium might be attributed to the active site competition of $\mathrm{MoS}_{2}$ between PRO and hydrogen ion ( $\mathrm{Li}$ et al. 2015). As can be seen from Fig. 5d, the stirring speed has little effect on the adsorption rate. The adsorption rate of PRO can reach $74.2 \%$ within $5 \mathrm{~min}$ even at $200 \mathrm{rpm}$. As depicted in Fig. 5e, although a low temperature was favorable for adsorption because it was an exothermic reaction, the saturated adsorption of $\mathrm{MoS}_{2}$ was almost unaffected by temperature in the range of $0-40{ }^{\circ} \mathrm{C}$. In addition, the appropriate temperature increase was beneficial to adsorption equilibrium. In order to reduce consumption, the adsorption process was operated for 5 min under the optimized conditions $\left(25^{\circ} \mathrm{C}, 350 \mathrm{rpm}, \mathrm{pH} 9\right.$, $0.05 \mathrm{~g} \mathrm{MoS}_{2} / 100 \mathrm{~mL}$ ).

\section{Removal effects of TFs and TPs using the PECO-MoS 2 technique}

Under the optimized process conditions, the actual water sample-spiked TFs (1.0 mg/L, PRO, TET, and DIN) were treated to remove parent compounds and their TPs synchronously. The residues of PRO, TET, and DIN in primary effluent were $0.368 \mathrm{mg} / \mathrm{L}, 0.253 \mathrm{mg} / \mathrm{L}$, and $0.0012 \mathrm{mg} / \mathrm{L}$ (close to detection limit), respectively, with the degradation rates of $63.3 \%, 74.7 \%$, and $99.9 \%$, respectively, after 30-min photoelectrocatalysis (Fig. 6a). After undergoing the adsorption of 5 min, the residues of PRO, TET, and DIN were declined to $0.0973 \mathrm{mg} / \mathrm{L}, 0.0617 \mathrm{mg} / \mathrm{L}$, and $0.0012 \mathrm{mg} / \mathrm{L}$, respectively, with the removal rates of $90.3 \%, 93.8 \%$, and $99.9 \%$, respectively. The mineralization degree of TFs in surface waters is shown in Fig. 6b. The ratio of $\mathrm{TOC}_{\mathrm{t}}$ (at $t \mathrm{~min}$ ) and $\mathrm{TOC}_{0}$ (initial value) was declined to 0.57 undergoing $30-\mathrm{min}$ photo-electrocatalysis. The $\mathrm{TOC}_{15}$ was slightly higher than $\mathrm{TOC}_{10}$, which might be attributed to the transformation of TFs to TPs. After the primary effluent was further treated for 5 min by $\mathrm{MoS}_{2}$ adsorption, the ratio of TOC/TOC 0 was declined to 0.12 , indicating that TFs and their TPs were removed by $88 \%$. This result could be corroborated by the following fact. When the secondary effluent was concentrated 20 times by the QuECHERS-based method, no TPs in the enriched sample were detected in the full scan mode of LC-MS/MS. This result showed that these TPs can be absorbed completely by the $\mathrm{MoS}_{2}$ particle. This fact may be explained by the van 
Fig. 6 Removal rates (a) of TFs in actual surface waters, and TOC removal rates $(\mathbf{b})\left(C_{0}=1.0 \mathrm{mg} / \mathrm{L}\right)$ under optimal process
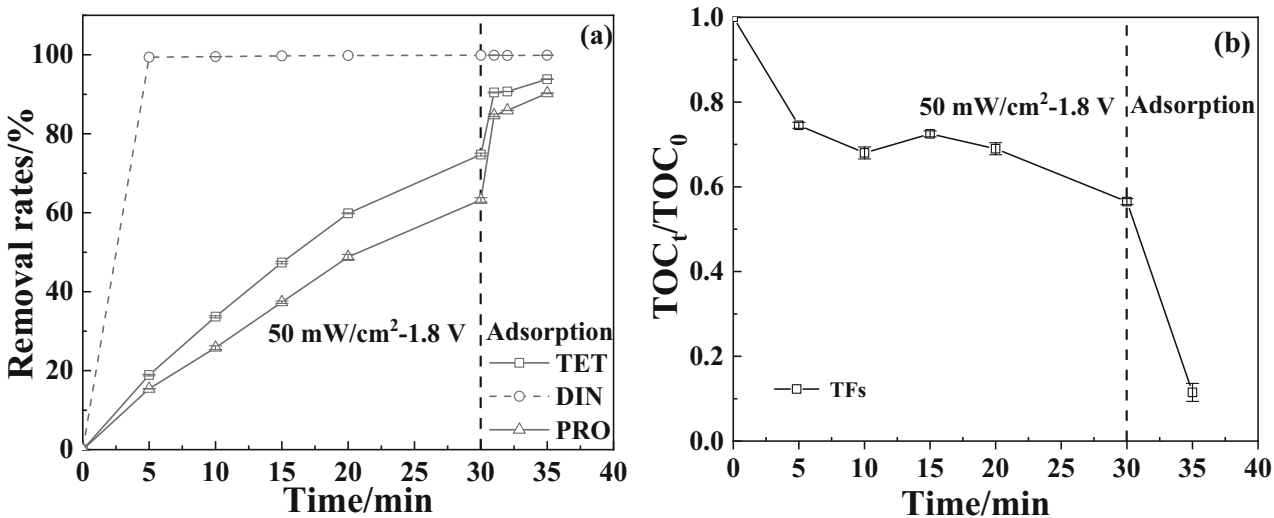

der Waals force between triazole heterocycle and the S-edges of $\mathrm{MoS}_{2}$. This theory was supported by Salazar et al. (2019). From here, we see that the nano-MoS $\mathrm{S}_{2}$ with a large specific surface area has been proved to be an excellent adsorbent to NHC-based pollutants, in view of similar nitrogen heterocycle structure.

\section{Potential cancer risk of effluent}

As described in Table S5, the potential cancer risk coefficients induced by individual TFs were $1.13 \times 10^{-8}$ (PRO), $7.78 \times$ $10^{-9}$ (TET), and $3.69 \times 10^{-11}$ (DIN), respectively, when TF aqueous solution was irradiated for $30 \mathrm{~min}$ by the reactor. In addition, the corresponding risk coefficients were further declined after undergoing 5-min adsorption by $\mathrm{MoS}_{2}$. Meanwhile, the total risk coefficients of three TFs were 1.91 $\times 10^{-8}$ (primary effluent) and $4.93 \times 10^{-9}$ (secondary effluent), respectively. In view of maximum risk principle, the cancer risks of three TFs were far below the safe drinking standard $\left(10^{-6}\right)$ when the carcinogenic potency index (1.0) for each was used for calculation. Because no TPs were observed in secondary effluent after $\mathrm{MoS}_{2}$ adsorption, there was no need to feel anxious about the risk contribution of TPs.

\section{Conclusion}

The typical TFs were photo-electrocatalytically degraded to a series of higher-polarity NHCs, and a tentative transformation pathway was proposed involving dehydrochlorination, cyclization, hydroxylation, etc. Although these TPs might pose potential aquatic toxicity, TFs and their TPs can be removed synchronously through the simple and effective tandem technique of PECO-MoS ${ }_{2}$ adsorption, especially in alkaline medium. The current study can provide theoretical basis for harmless treatment of TFs in the water environment. For better practical application, further research will be performed in the near future. For example, the magnetic $\mathrm{MoS}_{2}$-based adsorbent will be developed for facilitate recycling, simultaneous with regeneration method and recycling stability. Besides, the construction of doped photosensitive electrodes with higher oxygen evolution potential may be able to realize in situ synchronous mineralization of TFs and their TPs only by one-step photo-electrocatalysis.

Supplementary Information The online version contains supplementary material available at https://doi.org/10.1007/s11356-020-12185-x.

Acknowledgments We are grateful to the Bioengineering Technology Innovation Center of Hebei Province for the support of experiment instruments during this research. We are equally indebted to Jianfang Du for providing professional assistance in improving language.

Authors' contributions Xiaoxin Chen made substantial contributions to the conception or design of the work and was a major contributor in writing the manuscript; Junwen Wang and Jianfang Du made the acquisition, analysis, and interpretation of data in the work; Xiaoli Sun and Miao Liu revised the work for important intellectual content; Xingqiang $\mathrm{Wu}$ and Yichao Gong agree to be accountable for all aspects of the work in ensuring that questions related to the accuracy or integrity of any part of the work are appropriately investigated and resolved. All authors read and approved the final manuscript.

Funding This work was funded by the Natural Science Foundation of Hebei Province (grant numbers B2019201043; E2020201035); China Postdoctoral Science Foundation Project (grant number 2019M661043); the Science and Technology Support Program of Baoding City (grant number 18ZF314); and the Advanced Talents Incubation Program of the Hebei University (grant number 521000981225).

Data availability The datasets used and analyzed during the current study are available from the corresponding author on reasonable request.

\section{Compliance with ethical standards}

Ethical approval Not applicable.

Consent for publication Not applicable.

Consent for participation Not applicable.

Conflict of interest These authors declare that they have no conflict of interest. 
Open Access This article is licensed under a Creative Commons Attribution 4.0 International License, which permits use, sharing, adaptation, distribution and reproduction in any medium or format, as long as you give appropriate credit to the original author(s) and the source, provide a link to the Creative Commons licence, and indicate if changes were made. The images or other third party material in this article are included in the article's Creative Commons licence, unless indicated otherwise in a credit line to the material. If material is not included in the article's Creative Commons licence and your intended use is not permitted by statutory regulation or exceeds the permitted use, you will need to obtain permission directly from the copyright holder. To view a copy of this licence, visit http://creativecommons.org/licenses/by/4.0/.

\section{References}

Aparicio I, Martín J, Santos JL, Malvar JL, Alonso E (2017) Stir bar sorptive extraction and liquid chromatography-tandem mass spectrometry determination of polar and non-polar emerging and priority pollutants in environmental waters. J Chromatogr A 1500:43-52

Battaglin WA, Sandstrom MW, Kuivila KM, Kolpin DW, Meyer MT (2011) Occurrence of azoxystrobin, propiconazole, and selected other fungicides in US streams, 2005-2006. Water Air Soil Pollut 218: 307-322

Boxall ABA, Sinclair CJ, Fenner K, Kolpin D, Maund SJ (2004) When synthetic chemicals degrade in the environment. Environ Sci Technol 38:368A-375A

Ccanccapa A, Masia A, Navarro-Ortega A, Pico Y, Barcelo D (2016) Pesticides in the Ebro River basin: occurrence and risk assessment. Environ Pollut 211:414-424

Chen XX, Dong BZ, Lin HF, Hu JY (2016) Identification of photoproducts of fungicide cyprodinil and elucidation of transformation mechanism in water using LC-IT-TOF-MS/MS technique. Chemosphere. 160:359-365

Christensen PA, Curtis TP, Egerton TA, Kosa SAM, Tinlin JR (2003) Photoelectrocatalytic and photocatalytic disinfection of E. coli suspensions by titanium dioxide. Appl Catal B Environ 41: 371-386

Climent MJ, Herrero-Hernandez E, Sanchez-Martin MJ, Rodríguez-Cruz MS, Urrutia R (2019) Residues of pesticides and some metabolites in dissolved and particulate phase in surface stream water of Cachapoal River basin, central Chile. Environ Pollut 251:90-101

Crowell SR, Henderson WM, Kenneke JF, Fisher JW (2011) Development and application of a physiologically based pharmacokinetic model for triadimefon and its metabolite triadimenol in rats and humans. Toxicol Lett 205:154-162

Cui T, Zhang YG, Han WQ, Li JS, Sun XY, Shen JY, Wang LJ (2017) Advanced treatment of triazole fungicides discharged water in pilot scale by integrated system: enhanced electrochemical oxidation, upflow biological aerated filter and electrodialysis. Chem Eng J 315:335-344

Draskau MK, Boberg J, Taxvig C, Pedersen M, Frandsen HL, Christiansen S, Svingen T (2019) In vitro and in vivo endocrine disrupting effects of the azole fungicides triticonazole and flusilazole. Environ Pollut 255:113309

Elfikrie N, Ho YB, Zaidon SZ, Juahir H, Tan ESS (2020) Occurrence of pesticides in surface water, pesticides removal efficiency in drinking water treatment plant and potential health risk to consumers in Tengi River Basin, Malaysian. Sci Total Environ 712:136540

Garcia-Muñoz P, Dachtler W, Altmayer B, Schulz R, Robert D, Seitz F, Rosenfeldt R, Keller N (2020) Reaction pathways, kinetics, and toxicity assessment during the photocatalytic degradation of glyphosate and myclobutanil pesticides: influence of the aqueous matrix. Chem Eng J 384:123315
Grau J, Benede JL, Serrano J, Segura A, Chisvert A (2019) Stir bar sorptive-dispersive microextraction for trace determination of triphenyl and diphenyl phosphate in urine of nail polish users. J Chromatogr A 1593:9-16

Jaramillo-Gutiérrez MI, Carreno-Lizcano MI, Ruiz-Lizarazo JO, Pedraza-Avella JA, Rivero EP, Cruz-Díaz MR (2020) Design, mathematical modelling, and numerical simulation of a novel tubular photoelectrochemical reactor and experimental validation by residence time distribution and mass transfer coefficients. Chem Eng J 386:123895

Li XZ, Liu HL, Yue PT (2000) Photoelectrocatalytic oxidation of rose bengal in aqueous solution using a $\mathrm{Ti} / \mathrm{TiO}_{2}$ mesh Electrode. Environ Sci Technol 34:4401-4406

Li WP, Han XY, Wang XY, Wang YQ, Wang WX, Xu H, Tan TS, Wu WS, Zhang HX (2015) Recovery of uranyl from aqueous solutions using amidoximated polyacrylonitrile/exfoliated $\mathrm{Na}$ montmorillonite composite. Chem Eng J 279:735-746

Masis-Mora M, Lizano-Fallas V, Tortella G, Beita-Sandí W, Carlos E (2019) Rodriguez-Rodríguez. Removal of triazines, triazoles and organophophates in biomixtures and application of a biopurification system for the treatment of laboratory wastewaters. Chemosphere. 233:733-743

Matos DBD, Barbosa MPR, Leite OM, Steter JR, Lima NS, Torres NH, Marques MN, Alsina OLSD, Cavalcanti EB (2018) Characterization of a tubular electrochemical reactor for the degradation of the commercial diuron herbicide. Environ Technol 3330:1307-1321

Mazierski P, Borzyszkowska AF, Wilczewska P, Białk-Bielinska A, Zaleska-Medynska A, Siedlecka EM, Pieczynska A (2019) Removal of 5-fluorouracil by solar-driven photo-electrocatalytic oxidation using $\mathrm{Ti} / \mathrm{TiO}_{2}(\mathrm{NT})$ photoelectrodes. Water Res 157: $610-620$

Molinari R, Lavorato C, Argurio P (2017) Recent progress of photocatalytic membrane reactors in water treatment and in synthesis of organic compounds. A review. Catal Today 281:144-164

Ochiai N, Sasamoto K, Ieda T, David F, Sandra P (2013) Multi-stir bar sorptive extraction for analysis of odor compounds in aqueous samples. J Chromatogr A 1315:70-79

Rodgers JD, Bunce NJ (2001) Electrochemical treatment of 2,4,6trinitrotoluene and related compounds. Environ Sci Technol 35: 406-410

Rodríguez-Cabo T, Rodríguez I, Ramil M, Cela R (2018) Evaluation of the aqueous phototransformation routes of phenyl ethyl azolic fungicides by liquid chromatography accurate mass spectrometry. Sci Total Environ 615:942-954

Salazar N, Schmidt SB, Lauritsen JV (2019) Adsorption of nitrogenous inhibitor molecules on $\mathrm{MoS}_{2}$ and CoMoS hydrodesulfurization catalysts particles investigated by scanning tunneling microscopy. J Catal 370:232-240

Suhadolnik L, Pohar A, Novak U, Likozar B, Mihelič A, Ceh M (2019) Continuous photocatalytic, electrocatalytic and photoelectrocatalytic degradation of a reactive textile dye for wastewater-treatment processes: batch, microreactor and scaled-up operation. J Ind Eng Chem 72:178-188

Teng MM, Zhao F, Zhou YM, Yan S, Tian SN, Yan J, Meng ZY, Bi S, Wang CJ (2019) Effect of propiconazole on the lipid metabolism of zebrafish embryos (Danio rerio). J Agric Food Chem 67:46234631

Tian SN, Teng MM, Meng ZY, Yan S, Jia M, Li RS, Liu L, Yan J, Zhou ZQ, Zhu WT (2019) Toxicity effects in zebrafish embryos (Danio rerio) induced by prothioconazole. Environ Pollut 255:113269

Wang C, Wu QH, Wu CX, Wang Z (2011) Application of dispersionsolidification liquid-liquid microextraction for the determination of triazole fungicides in environmental water samples by highperformance liquid chromatography. J Hazard Mater 185:71-76 
Wang H, Liang YH, Liu L, Hu JS, Wu P, Cui WQ (2017) Enriched Photoelectrocatalytic degradation and photoelectric performance of BiOI photoelectrode by coupling rGO. Appl Catal B Environ 208: 22-34

Wu HB, Shen JY, Jiang XB, Liu XD, Sun XY, Li JS, Han WQ, Mu Y, Wang LJ (2018) Bioaugmentation potential of a newly isolated strain Sphingomonas sp. NJUST37 for the treatment of wastewater containing highly toxic and recalcitrant tricyclazole. Bioresour Technol 264:98-105

Wu HB, Sun QQ, Sun YL, Zhou YK, Wang J, Hou C, Jiang XB, Liu XD, Shen JY (2019) Co-metabolic enhancement of 1H-1,2,4-triazole biodegradation through nitrification. Bioresour Technol 271:236243
Ying G, Luo SL (2017) Degradation of azole fungicide fluconazole in aqueous solution by thermally activated persulfate. Chem Eng J 321: $113-122$

Zhang ZX, Gao BB, He ZZ, Li LS, Shi HY, Wang MH (2019) Enantioselective metabolism of four chiral triazole fungicides in rat liver microsomes. Chemosphere. 224:77-84

Zhang NQ, Xue CJ, Wang K, Fang ZQ (2020) Efficient oxidative degradation of fluconazole by a heterogeneous Fenton process with $\mathrm{Cu}-$ V bimetallic catalysts. Chem Eng J 380:122516

Zhao X, Guo LB, Qu JH (2014) Photoelectrocatalytic oxidation of CuEDTA complex and electrodeposition recovery of $\mathrm{Cu}$ in a continuous tubular photoelectrochemical reactor. Chem Eng J 239:53-59

Publisher's note Springer Nature remains neutral with regard to jurisdictional claims in published maps and institutional affiliations. 